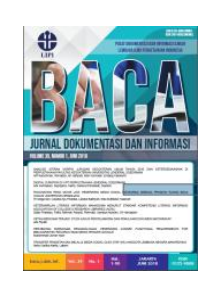

\title{
EVALUASI GUIDELINE DAN E-LEARNING DIGITAL LITERACY MENGGUNAKAN MODEL CIPP
}

\author{
Winda Anestya Ayunda ${ }^{1 *}$, Yani Nurhadryani ${ }^{2}$, Sony Wijaya ${ }^{3}$ \\ ${ }^{1}$ Magister Teknologi Informasi untuk Perpustakaan, Institut Pertanian Bogor \\ ${ }^{1}$ Peneliti Pusat Penelitian dan Manajemen IPTEK, LIPI \\ ${ }^{2}$ Departemen Ilmu Komputer, Institut Pertanian Bogor \\ ${ }^{3}$ Departemen Ilmu Komputer, Institut Pertanian Bogor \\ *Korespondensi:windaanestya@gmail.com
}

Diajukan: 08-05-2019; Direview: 02-07-2019; Diterima: 08-08-2019; Direvisi: 09-01-2020

\begin{abstract}
This study aims to evaluate digital literacy guidelines based on blended learning using the CIPP model (Contexts, Inputs, Processes, Products). The research method is simple experimental, namely by distributing questionnaires to users who have carried out trials on the system. The source of research data is librarians in the Center for Scientific Documentation and Information. Evaluation is measured by looking at the agreement and disagreement of users regarding the topic of training, completeness of the material, training time, and system quality. The results of the study show that the guidelines and elearning are declared quite effective. However, there are still some disadvantages, among others, that there is still a small format of teaching material in applications, such as visual content, namely images, videos and audio to be used as reference for learning. In addition, an evaluation of the timing of training is needed.
\end{abstract}

\begin{abstract}
ABSTRAK
Penelitian ini bertujuan untuk mengevaluasi guideline literasi digital berbasis blended learning menggunakan model CIPP (Contexts, Input, prosess, Product). Penelitian menggunakan metode eksperimental sederhana yaitu dengan cara menyebarkan kuesioner kepada pengguna yang telah melakukan uji coba pada sistem. Sumber data penelitian adalah pustakawan di Pusat Dokumentasi dan Informasi Ilmiah, Lembaga Ilmu Pengetahuan Indonesia. Evaluasi diukur dengan melihat kesetujuan dan ketidak setujuan pengguna terjadap topik pelatihan, kelengkapan materi, waktu pelatihan, dan kualitas sistem. Hasil penelitian menunjukan bahwa guideline dan e-learning dinyatakan cukup efektif. Namun masih terdapat beberapa kekurangan diantaranya, masih sedikitnya format materi ajar pada aplikasi, seperti konten visual yaitu gambar, video dan audio untuk dijadikan referensi pembelajaran. Selain itu diperlukan evaluasi terhadap waktu penyelenggaraan pelatihan.
\end{abstract}

Keywords: Digital literacy; E-learning; CIPP model; Guideline evaluation; LIPI

\section{PENDAHULUAN}

Digital literacy merupakan kemampuan yang harus dimiliki oleh masyarakat agar teknologi yang semakin canggih berdampak positif pada kemajuan wilayahnya. Beberapa kasus seperti kurang maksimalnya sistem yang dibuat pemerintah, berita hoaxs, dan cyberbullying, menunjukkan perlunya tindakan untuk meminimalisasi dampak buruk teknologi di masyarakat (Hamilton, 2016). 
Penelitian ini menjelaskan tentang desain e-learning untuk pelatihan digital literacy. Pelatihan ini dirancang dengan metode blended learning, yaitu menggabungkan pembelajaran tatap muka dan memanfaatkan jaringan internet sebagai sarana penyampaian bahan ajar (modul) yang diubah ke format digital. Pelatihan dirancang agar dapat dilaksanakan oleh perpustakaan pemerintah, perpustakaan swasta, atau organisasi masyarakat yang bergerak dalam bidang literasi.

Topik pelatihan mengacu pada BC's Digital literacy framework yang di keluarkan oleh British Colombia Library pada tahun 2015. Framework ini membagi indikator digital literacy, yaitu Research and Information Literacy; Critical Thinking; Digital Literacy; Creativity and Innovation; Communication and Collaboration; Technology Operation and Concepts. Penelitian menghasilkan sebuah modul pembelajaran yang dilengkapi dengan guideline berupa Garis-garis Besar Pelatihan (GGBP). Modul diubah ke format digital dan diintegrasikan dengan platform e-learning berbasis moodle.

Alur pelatihan mencakup: (1) pre-test online, sebagai evaluasi awal untuk mengetahui kemampuan peserta sebelum mengikuti pelatihan; (2) melaksanakan pelatihan, terdiri dari penyampaian teori sebagai pengantar pembelajaran, praktik penggunaan teknologi, menganalisis kasus-kasus dalam lingkungan digital, dan menciptakan sebuah produk dari media digital; (3) pada akhir setiap sesi pembelajaran, peserta wajib menyelesaikan kuis menggunakan platform e-learning digital literacy.

Dalam proses belajar mengajar selalu diikuti kegiatan evaluasi. Evaluasi merupakan suatu kegiatan untuk mengetahui apakah proses belajar mengajar telah mencapai tujuan yang sudah ditetapkan atau belum, dengan kata lain proses belajar mengajar belum diketahui berhasil jika belum dilakukan evaluasi (Bakhti, 2017). Guideline, modul, dan e-learning yang telah dirancang belum dievaluasi sehingga belum dapat diukur tingkat keberhasilannya. Selain itu, produk juga membutuhkan saran dari pustakawan - mereka dianggap memahami konsep digital literacy. Evaluasi terhadap produk dokumen tersebut menggunakan model CIPP (Contexts, Input, Prosess, Product). Model CIPP ini dapat digunakan untuk memperoleh umpan balik terhadap topik penelitian, waktu pelatihan, kualitas sistem, dan kelayakan sistem. Parameter ini diharapkan dapat memberikan gambaran mengenai bagaimana tingkat kesiapan produk untuk dapat diterapkan oleh perpustakaan.

\section{TINJAUAN PUSTAKA}

\subsection{Digital literacy}

Istilah digital literacy pertama kali dicetuskan oleh Paul Gilster dalam bukunya "digital literacy" yaitu pada tahun 1997. Dalam buku tersebut, dijelaskan literasi digital sebagai kemampuan menggunakan teknologi dan informasi dalam berbagai format maupun berbagi sumber yang berasal dari perangkat digital khususnya media internet (Lankshear, et al, 2006). Digital literacy tidak hanya sekedar kemampuan untuk menggunakan komputer, tetapi juga kemampuan untuk memahami dan menafsirkan informasi yang tersedia di semua media digital.

\subsection{Blended Learning}

Salah satu metode pelatihan digital literacy adalah blended learning. Metode ini merupakan proses belajar mengajar yang menggabungkan sistem tatap muka dengan information and comunication technology. Peserta pelatihan tidak hanya diminta untuk 
mengikuti pelajaran di dalam kelas namun juga sistem belajar jarak jauh. Metode ini memanfaatkan teknologi dengan menggunakan jaringan internet sebagai sarana penyampaian bahan ajar (modul) yang telah diubah ke format digital (pdf./ppt.). Dalam konteks penelitian ini, media digital yang digunakan adalah aplikasi learning platform.

Platform pembelajaran adalah serangkaian layanan online interaktif yang memberi peserta akses ke informasi, alat, dan sumber daya untuk mendukung pengiriman dan pengelolaan pendidikan melalui internet. Penelitian yang dilakukan oleh Lim (2007) mengungkapkan bahwa proses pembelajaran yang hanya mengandalkan metode e-learning ternyata kurang efektif, karena siswa hanya mengandalkan konten elektronik. Sementara itu dalam pendekatan blended learning, siswa mengungkapkan lebih banyak belajar, berdiskusi kelompok, dan berinteraksi dengan tutor.

\subsection{Guideline Digital Literacy}

Berdasarkan Undang-Undang Nomor 43 tahun 2007 tentang Perpustakaan, Pasal 29 ayat (1) dijelaskan bahwa peningkatan kualitas tenaga perpustakaan dapat dilakukan melalui pendidikan dan pelatihan bidang perpustakaan. Dalam rangka memenuhi kompetensi tersebut, perlu didukung adanya kurikulum dan bahan ajar yang mengacu pada standar kompetensi yang dibutuhkan dan mengikuti perkembangan terkini di bidang perpustakaan, dokumentasi dan informasi. Kurikulum dan bahan ajar diklat tersebut dikenal dengan istilah GGBP.

Dokumen GGBP digunakan sebagai acuan pembelajaran dan buku pedoman bagi widyaswara/pengajar dan peserta diklat untuk memudahkan mereka dalam mencapai tujuan pembelajaran. GGBP digital literacy dirancang dengan komponen, yang terdiri dari topik mata pelatihan, sub-pokok bahasan, tujuan instruksional khusus, metode dan estimasi waktu pembelajaran. Struktur GGBP dapat dilihat pada Tabel 1.

Tabel 1. Rancangan GGBP Pelatihan Digital Literacy

\begin{tabular}{|c|c|c|c|c|c|}
\hline No. & Indikator Keberhasilan & Sesi/ Pelatihan & Persediaan & Metode & $\begin{array}{c}\text { Est. } \\
\text { Waktu }\end{array}$ \\
\hline 1 & $\begin{array}{l}\text { Peserta pelatihan mampu memanfaatkan } \\
\text { media digital untuk mengumpulkan, } \\
\text { mengevaluasi, dan menggunakan } \\
\text { informasi. }\end{array}$ & Tatap Muka ke-I & $\begin{array}{l}\text { Buku-buku } \\
\text { Alat Tulis } \\
\text { Laptop }\end{array}$ & $\begin{array}{l}\text { Presentasi } \\
\text { Praktek } \\
\text { Diskusi terbuka }\end{array}$ & $\begin{array}{c}120 \\
\text { menit }\end{array}$ \\
\hline 2 & $\begin{array}{l}\text { Peserta pelatihan mermiliki kemampuan } \\
\text { berpikir kritis untuk merencanakan dan } \\
\text { mengadakan penelitian, mengelola projek, } \\
\text { menyelesaikan masalah, dan membuat } \\
\text { keputusan menggunakan peralatan dan } \\
\text { sumber daya digital yang selayaknya. }\end{array}$ & Tatap Muka ke-II & $\begin{array}{l}\text { Buku-buku } \\
\text { Alat Tulis } \\
\text { Laptop }\end{array}$ & $\begin{array}{l}\text { Presentasi } \\
\text { Praktek } \\
\text { Diskusi } \\
\text { Kelompok }\end{array}$ & $\begin{array}{c}120 \\
\text { menit }\end{array}$ \\
\hline 3 & $\begin{array}{l}\text { Peserta Pelatihan Memahami konsep } \\
\text { terkait dengan teknologi khususnya dalam } \\
\text { jejaring sosial, dengan menunjukkan } \\
\text { perilaku yang bertanggung jawab, sesuai } \\
\text { dengan norma dan etika yang berlaku. }\end{array}$ & $\begin{array}{l}\text { Tatap Muka ke-III } \\
\text { dan ke IV }\end{array}$ & $\begin{array}{l}\text { Buku-buku } \\
\text { Alat Tulis } \\
\text { Laptop }\end{array}$ & $\begin{array}{l}\text { Presentasi } \\
\text { Praktek } \\
\text { Diskusi } \\
\text { Kelompok } \\
\text { games }\end{array}$ & $\begin{array}{c}270 \\
\text { menit }\end{array}$ \\
\hline 4 & $\begin{array}{l}\text { Peserta pelatihan Menunjukkan pemikiran } \\
\text { kreatif, membangun pengetahuan dan } \\
\text { pengembangan produk inovasi dan proses } \\
\text { menggunakan teknologi. }\end{array}$ & Tatap Muka ke-V & $\begin{array}{l}\text { Buku-buku } \\
\text { Alat Tulis } \\
\text { Laptop }\end{array}$ & $\begin{array}{l}\text { Presentasi } \\
\text { Praktek } \\
\text { Diskusi } \\
\text { Kelompok } \\
\text { games }\end{array}$ & $\begin{array}{c}120 \\
\text { menit }\end{array}$ \\
\hline 5 & $\begin{array}{l}\text { Peserta pelatihan Menggunakan media } \\
\text { digital untuk berbagi, berkomunikasi dan } \\
\text { berkolaborasi dengan orang lain secara } \\
\text { efektif di lingkungan digital. }\end{array}$ & Tatap Muka ke-VI & $\begin{array}{l}\text { Buku-buku } \\
\text { Alat Tulis } \\
\text { Laptop }\end{array}$ & $\begin{array}{l}\text { Presentasi } \\
\text { Praktek } \\
\text { Diskusi terbuka }\end{array}$ & $\begin{array}{c}90 \\
\text { menit }\end{array}$ \\
\hline
\end{tabular}




\begin{tabular}{|c|c|c|c|c|c|}
\hline No. & Indikator Keberhasilan & Sesi/ Pelatihan & Persediaan & Metode & $\begin{array}{c}\text { Est. } \\
\text { Waktu }\end{array}$ \\
\hline 6 & $\begin{array}{l}\text { Peserta pelatihan Menunjukan pemahaman } \\
\text { yang baik tentang konsep, sistem maupun } \\
\text { dalam mengoperasikan teknologi dan } \\
\text { mengembangkan kemampuan berpikir } \\
\text { komputasi. }\end{array}$ & $\begin{array}{l}\text { Tatap Muka ke- } \\
\text { VII }\end{array}$ & $\begin{array}{l}\text { Buku-buku } \\
\text { Alat Tulis } \\
\text { Laptop }\end{array}$ & $\begin{array}{l}\text { Presentasi } \\
\text { Praktek } \\
\text { Diskusi terbuka }\end{array}$ & $\begin{array}{c}120 \\
\text { menit }\end{array}$ \\
\hline
\end{tabular}

Sumber: Ayunda (2018)

GBBP digital literacy disusun dengan sistematik dan mencakup deskripsi materi, tujuan, pokok bahasan, metode dan media, serta sumber bahan yang diperlukan untuk pelatihan. Metode pembelajaran yang digunakan adalah ceramah, diskusi, praktek dan tugas. Indikator keberhasilan GBPP adalah peserta pelatihan memiliki kemampuan dalam menemukan informasi, mengakses informasi, mengevaluasi informasi, berfikir kritis, kreatif dan inovatif, paham konsep teknologi dan menggunakan informasi sesuai etika dunia digital.

\subsection{E-learning}

E-learning pelatihan digital literacy merupakan salah satu strategi untuk meningkatkan kompetensi peserta pelatihan. Pemanfaatan teknologi pelatihan e-learning fokus pada akses peserta dan pemateri untuk meng-upload atau download modul, menilai/membahas latihan soal, dan komunikasi dalam forum chat. Untuk mewujudkan hal itu, pelatihan e-learning menggunakan aplikasi Moodle sebagai media pembelajaran. Aplikasi Moodle menggunakan sistem antarmuka pengguna yang dapat disesuaikan dengan kebutuhan pelatihan dan bersifat open source. Aplikasi e-learning dapat digunakan untuk tiga pengguna, yaitu admin, peserta, dan pengajar. Perbedaan akses terletak pada menu registrasi, yang hanya dapat diakses oleh admin, menu upload, membuat kuis (yang hanya dapat diakses pengajar), unduh materi, dan mengerjakan kuis (yang dapat diakses oleh peserta pelatihan). Gambar 1 merupakan contoh tampilan database e-learning digital literacy.

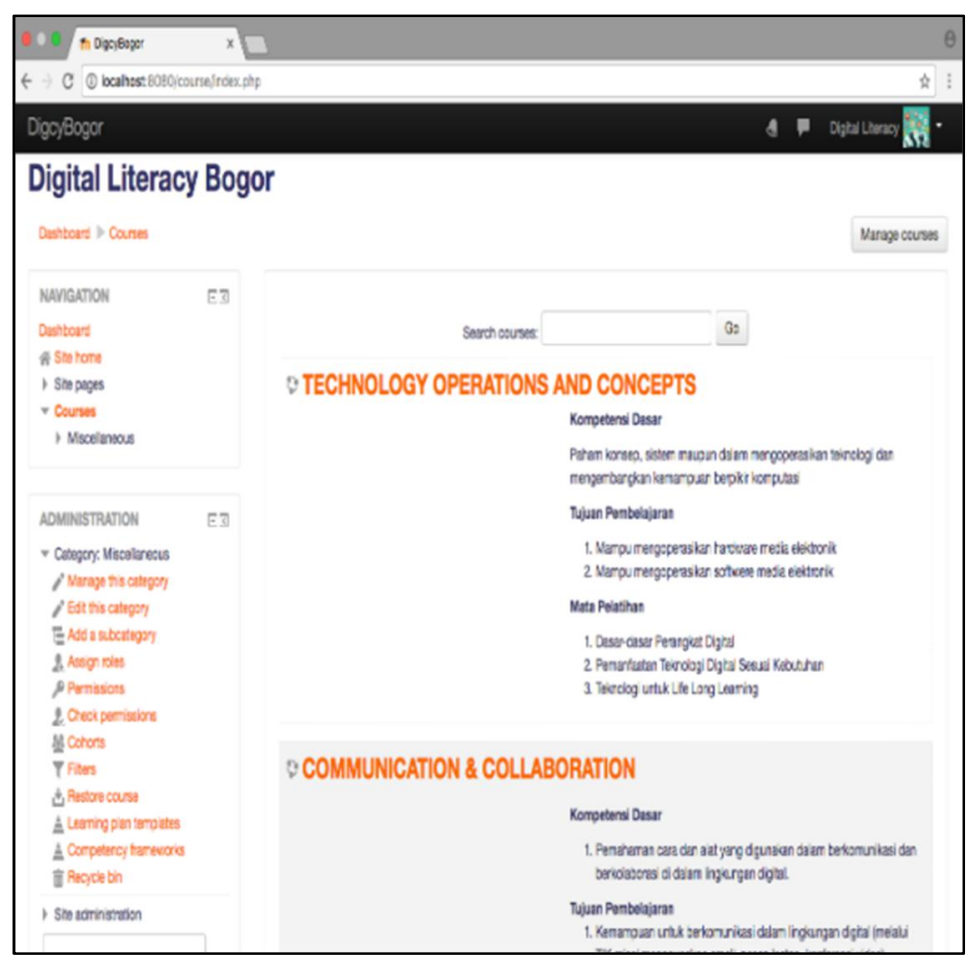




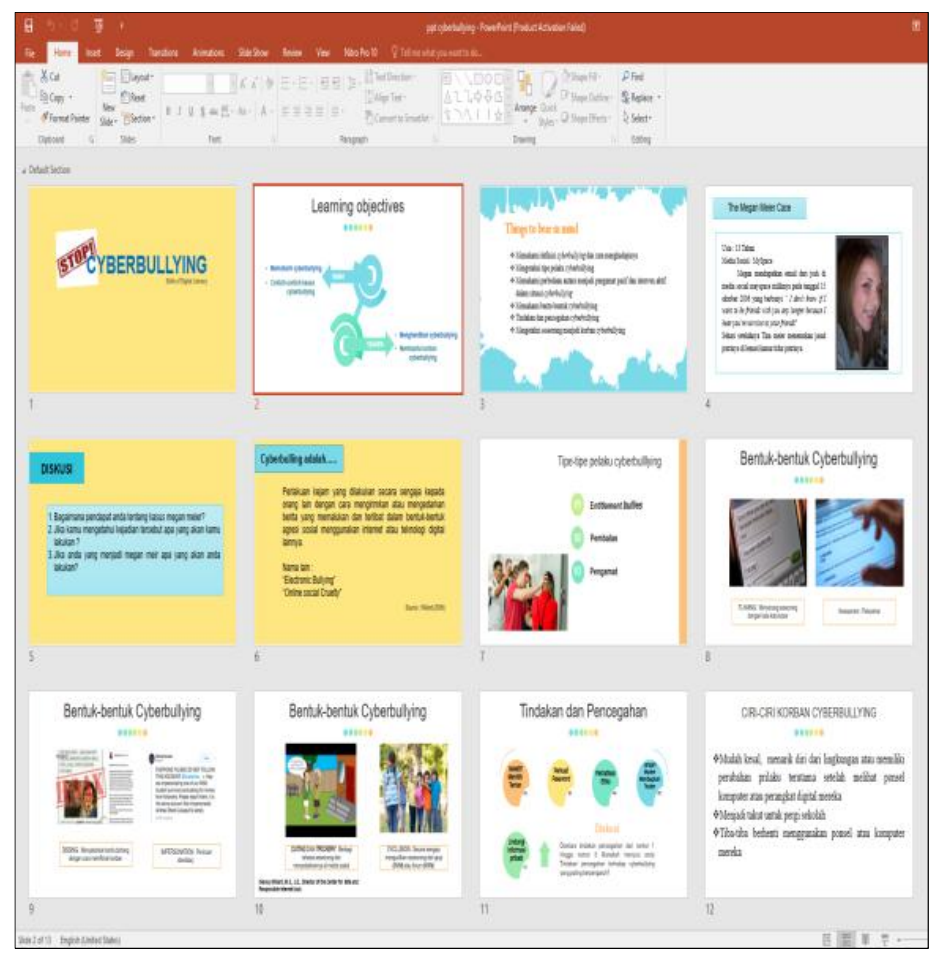

Gambar 1. Tampilan database e-learning digital literacy

Manfaat e-learning adalah melaksanakan penilaian online dalam pembelajaran. Pre-test dan post-test yang dilaksanakan di awal dan akhir pembelajaran telah diintegrasikan ke platformlearning. Format penilaian post-test pertanyaan disusun dalam bentuk true or false, multiple choices, dan shortessay. Pada akhir pembelajaran, siswa diberikan kuis untuk menguji daya ingat dan kemampuan mereka (Gambar 2).

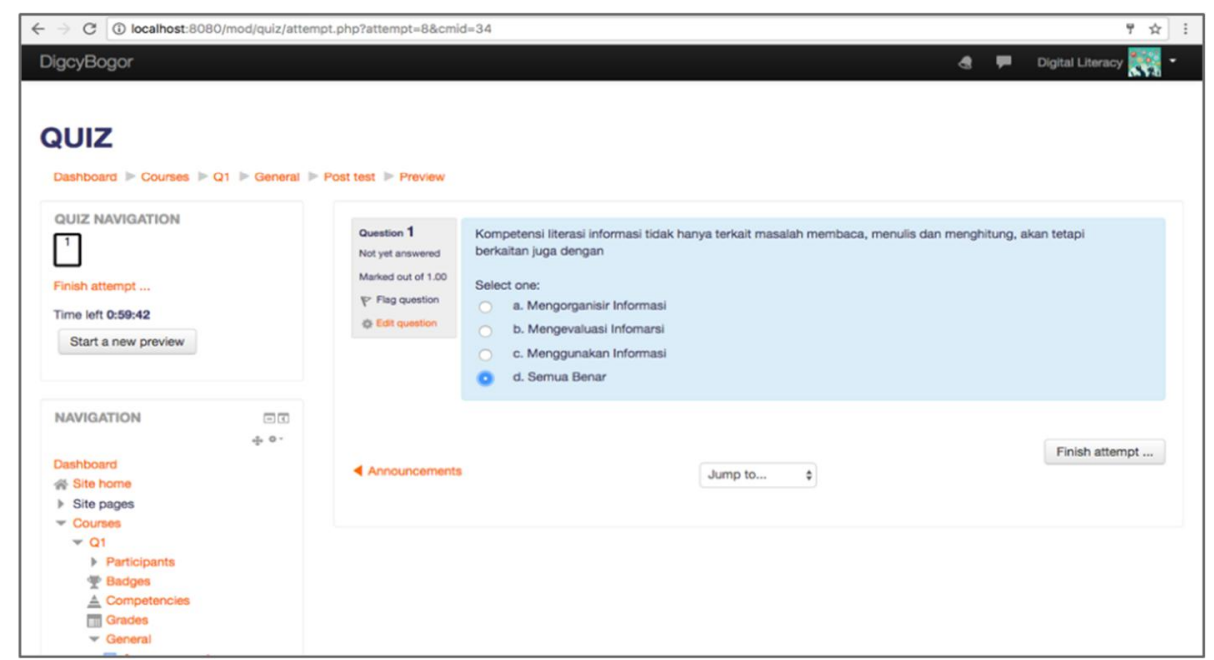

Gambar 2. Halaman kuis mata pelajaran literasi Informasi

Tingkat kesulitan penilaian masih dalam kategori sedang, karena soal-soal hanya diambil dari seputaran materi yang telah dipaparkan dalam modul. Untuk itu, diperlukan saran dari 
para pakar untuk mengevaluasi materi dan soal-soal, apakah sudah menginterpretasikan kemampuan digital literacy peserta atau belum.

\subsection{Evaluasi Guideline Digital literacy}

Menurut Mahmudi (2011), evaluasi program pembelajaran merupakan studi yang sistematis dan didesain, dilaksanakan, serta dilaporkan untuk membantu klien memutuskan dan/atau meningkatkan keberhargaan dan/atau manfaat program pembelajaran. Meskipun modul yang dirancang mengacu pada framework yang dikeluarkan oleh salah satu perpustakaan terbaik di dunia, namun masih diperlukan tinjauan ulang secara nyata untuk membuktikan kelayakan modul sebagai sarana pembelajaran. Meskipun dibangun dengan platform e-learning terpercaya, namun harus diuji coba terlebih dahulu untuk melihat tingkat kesuksesannya.

Dalam ilmu evaluasi di dunia pendidikan, ada banyak metode yang dapat dilakukan untuk mengevaluasi suatu program. Salah satunya yaitu model CIPP. Model ini pertamakali dicetuskan oleh Stufflebeam pada tahun 1983. Model CIPP merupakan singkatan dari Context, Input, Process, dan Product. Elemen penting yang menjadikan model ini berbeda dari model lain adalah adanya konteks untuk evaluasi proses belajar mengajar dan pengembangan (Aziz et al. 2018). Model ini digunakan untuk mengevaluasi secara summative dan formative. Keunggulan dari model ini adalah tersedianya pandangan holistik dari setiap elemen untuk mengevaluasi konteks, input, proses dan output dari setiap sudut pandang. Dengan bantuan model ini, evaluasi dapat dilakukan secara sistematis.

\section{METODE}

Evaluasi dilakukan dengan mensosialisasikan e-learning yang telah terintegrasi dengan guideline dan modul kepada 10 orang pustakawan di Pusat Dokumentasi dan Informasi Ilmiah - Lembaga Ilmu Pengetahuan Indonesia (PDII - LIPI), dan selanjutnya mereka diminta untuk mengisi evaluasi melalui lembar kuesioner. Kuesioner mengadopsi model CIPP, yaitu latar (context), masukan (input), proses (process), dan hasil (product). Hasil kuesioner dianalisis secara deskriptif. Perhitungan data kuesioner menggunakan skala Likert. Tujuannya untuk melihat tingkat persetujuan responden terhadap keefektifan modul dan e-learning. Variabel yang diukur kemudian dijabarkan menjadi indikator untuk menyusun instrumen pertanyaan, yang jawabannya diberi bobot/skor. Bobot/skor yang diberikan pada skala Likert dapat dilihat pada Tabel 2

Tabel 2. Skala Likert Penelitian

\begin{tabular}{|l|c|}
\hline \multicolumn{1}{|c|}{ Keterangan } & Bobot / Skor \\
\hline Sangat Tidak Setuju (STS) & 1 \\
\hline Tidak Setuju (TS) & 2 \\
\hline Kurang Setuju (KS) & 3 \\
\hline Setuju (S) & 4 \\
\hline Sangat Setuju (SS) & 5 \\
\hline
\end{tabular}

Sumber: Sugiyono (2017)

Dalam menentukan sampel, salah satu dari empat aturan praktis untuk menentukan ukuran sampel, yaitu pada penelitian eksperimental dengan kontrol yang ketat. Menurut Rosce (1975) dalam Sekaran (2013) penelitian dengan tipe ini dapat berhasil, jika sampel minimal 
antara $10-20$ orang. Penelitian ini menggunakan metode reaksi pengguna dengan sampel 10 orang. Masing-masing responden akan mendapatkan penjelasan mengenai produk secara mendalam. Tujuannya agar hasil evaluasi lebih terjamin kualitasnya. Perhitungan skor dilakukan dengan manual. Tabel 3 menunjukkan 4 konstruk yang menjadi parameter untuk mengidentifikasi reaksi pengguna terhadap guideline dan e-learning digital literacy.

Tabel 3. Konstruk Parameter Reaksi Pengguna

\begin{tabular}{|c|c|}
\hline Konstruk & Identifikasi Reaksi \\
\hline Context & $\begin{array}{l}\text { - } \quad \text { Ketertarikan peserta terhadap topik pelatihan } \\
\text { - } \quad \text { Pemahaman peserta terhadap materi ajar } \\
\text { - } \quad \text { Manfaat materi ajar untuk kehidupan sehari-hari }\end{array}$ \\
\hline Input & $\begin{array}{l}\text { - Identifikasi kepuasan peserta terhap contoh-contoh kasus dalam } \\
\text { memahami materi }\end{array}$ \\
\hline Process & $\begin{array}{l}\text { - } \quad \text { Perbandingan waktu pelatihan dengan banyaknya materi } \\
\text { - } \quad \text { Identifikasi pengguna saat menggunakan e-learning } \\
\text { - } \quad \text { Identifikasi kemudahan peserta saat mengakses materi pada } e \text { - } \\
\text { learning }\end{array}$ \\
\hline Product & $\begin{array}{ll}\text { - } & \text { Identifikasi kualitas tampilan e-learning } \\
\text { - } & \text { Identifikasi kesulitan melaksanakan kuis pada e-learning } \\
\text { - } & \text { Identifikasi kesesuaian soal-soal pada kuis dengan materi }\end{array}$ \\
\hline
\end{tabular}

\section{HASIL DAN PEMBAHASAN}

\subsection{Karakteristik Responden}

Karakteristik responden dilihat dari 3 indikator yaitu jenis kelamin, usia, dan pendidikan. Usia dibagi menjadi 2 kelompok sesuai dengan target peserta pelatihan, yaitu usia $23-34$ tahun dan usia 35-45 tahun. Kategori pendidikan dibagi menjadi 3 kelompok, yaitu Diploma, S1, dan S2. Tabel 4 menunjukkan karakteristik responden penelitian.

Tabel 4. Karakteristik Responden

\begin{tabular}{|c|c|c|}
\hline Karakteristik & Keterangan & Jumlah \\
\hline Jenis Kelamin & Laki-laki & 6 \\
& Perempuan & 4 \\
\hline Usia (tahun) & $25-34$ & 7 \\
& $35-45$ & 3 \\
\hline Pendidikan & Diploma & 2 \\
& S1 & 7 \\
& S2 & 1 \\
\hline
\end{tabular}

\subsection{Evaluasi Reaksi Pengguna}

Evaluasi reaksi pengguna menggunakan sistem scoring, yaitu menghitung nilai rata-rata (mean), dari jumlah pilihan dan dibagi total pertanyaan. Rumus yang digunakan sebagai berikut.

\section{(Jumlah Pilihan) x (Skala Likert) $=$ Skor}

Evaluasi menggunakan scoring bertujuan untuk menentukan nilai indikator sehingga dapat dilakukan proses identifikasi. Kriteria indikator merupakan standar yang digunakan untuk menilai keberhasilan program yang dievaluasi. 


\section{Evaluasi terhadap dimensi konteks}

Evaluasi konteks bertujuan untuk mengetahui kekuatan dan kelemahan pada produk. Setiap indikator diukur dengan menguji reaksi pengguna terhadap 3 pernyataan untuk mengidentifikasi kebutuhan yang tidak terpenuhi serta tujuan dari produk. Pernyataan yang dievaluasi mengenai ketertarikan pengguna terhadap topik pelatihan, kemudahan pengguna memahami materi, dan kebermanfaatan pelatihan. Hasil perhitungan score untuk variabel konteks dengan 10 responden dapat dilihat pada Tabel 5.

Tabel 5. Hasil Perhitungan Scoring Evaluasi Konteks

\begin{tabular}{|c|c|c|c|c|c|c|c|}
\hline \multirow[b]{2}{*}{ No. } & \multirow[b]{2}{*}{ Indikator } & \multicolumn{5}{|c|}{ Tanggapan Responden } & \multirow[b]{2}{*}{ SKOR } \\
\hline & & $\begin{array}{r}\text { STS } \\
\text { (1) }\end{array}$ & $\begin{array}{l}\mathrm{TS} \\
\text { (2) }\end{array}$ & $\begin{array}{c}\mathrm{KS} \\
(3)\end{array}$ & $\begin{array}{l}\text { S } \\
(4)\end{array}$ & $\begin{array}{l}\text { SS } \\
(5)\end{array}$ & \\
\hline 1 & Topik Guideline sangat menarik & 0 & 0 & 0 & 6 & 4 & 4,4 \\
\hline 2 & Materi ajar mudah dipahami & 0 & 0 & 1 & 8 & 1 & 4 \\
\hline 3 & $\begin{array}{l}\text { Materi ajar bisa diterapkan di } \\
\text { kehidupan sehari-hari }\end{array}$ & 0 & 0 & 1 & 5 & 4 & 4,3 \\
\hline \multicolumn{7}{|c|}{ Rata-rata } & 4.2 \\
\hline
\end{tabular}

Sebanyak 1 orang peserta mengalami kesulitan untuk memahami materi dan 4 orang peserta sangat setuju jika materi pada modul dapat diterapkan pada kehidupan sehari-hari. Mayoritas peserta menyatakan "setuju" jika topik guideline menarik untuk dipelajari - karena masih sedikitnya pelatihan digital literacy dan peserta belum mengetahui lebih banyak tentang $B C$ 's Digital Literacy. Evaluasi ini digunakan untuk menilai seluruh indikator, mengidentifikasi kelemahannya, menginventarisasi kekuatannya yang bisa dimanfaatkan untuk menutupi kelemahannya (Mahmudi, 2011). Analisis konteks juga mendapatkan respon positif dari responden (Bhakti, 2017). Evaluasi konteks menjadi gambaran dan spesifikasi tentang kebutuhan yang akan dicapai dari sistem sehingga seringkali menghadirkan hal baru yang menarik dan mudah dipahami pengguna.

\section{Evaluasi terhadap dimensi input}

Evaluasi input dilakukan untuk melihat kekurangan produk dari segi kebutuhan yang tidak terpenuhi. Pada penelitian ini, dimensi input menguji reaksi pengguna terhadap 3 pernyataan, yaitu tentang: (1) contoh kasus pada materi dalam membantu peserta memahami topik pembelajaran; (2) format bahan ajar e-learning; (3) dan kesesuaian soal-soal pada kuis dengan materi ajar. Hasil perhitungan score untuk indikator input dengan 10 responden dapat dilihat pada Tabel 6 .

Tabel 6. Hasil Perhitungan Scoring Evaluasi Input

\begin{tabular}{|c|l|c|c|c|c|c|c|}
\hline \multirow{2}{*}{ No. } & \multicolumn{1}{|c|}{ Indikator } & \multicolumn{4}{c|}{ Tanggapan Responden } & \\
\cline { 3 - 6 } & & $\begin{array}{c}\text { STS } \\
(1)\end{array}$ & $\begin{array}{c}\text { TS } \\
(2)\end{array}$ & $\begin{array}{c}\text { KS } \\
(3)\end{array}$ & $\begin{array}{c}\text { S } \\
(4)\end{array}$ & $\begin{array}{c}\text { SS } \\
(5)\end{array}$ & SKOR \\
\hline 1 & $\begin{array}{l}\text { Diberikannya contoh studi kasus membantu } \\
\text { peserta dalam memahami materi }\end{array}$ & 0 & 0 & 3 & 2 & 5 & 4,2 \\
\hline 2 & $\begin{array}{l}\text { e-learning menyediakan konten materi yang } \\
\text { beragam (PDF, Video, Power Point dsb) }\end{array}$ & 0 & 0 & 1 & 8 & 1 & 4 \\
\hline 3 & $\begin{array}{l}\text { Ketersediaan soal-soal pada e-learning } \\
\text { sesuai dengan materi ajar }\end{array}$ & 0 & 0 & 1 & 9 & 0 & 3,9 \\
\hline \multicolumn{2}{|l|}{ Rata-rata }
\end{tabular}


Tabel 6 menunjukkan jika mayoritas tanggapan peserta pelatihan berada pada kategori Setuju (S). Peserta mengetahui jika format pada bahan ajar bervariasi dan ketersediaan soalsoal pada menu kuis sesuai dengan bahan ajar. Hasil scoring menunjukkan rata-rata nilai 4. Dengan skala setuju. Jika dibandingkan dengan dimensi konteks, dimensi input sering mengalami respon yang sedikit lebih rendah. Menurut Setiyaningrum (2016), evaluasi input seharusnya memberikan informasi untuk menentukan bagaimana sistem dapat mencapai tujuan dan sasaran yang diinginkan. Dengan demikian, responden memberikan harapan yang cukup besar pada dimensi ini.

\section{Evaluasi terhadap dimensi proses}

Evaluasi proses bertujuan untuk mendeteksi rancangan produk selama tahap implementasi, pada dasarnya evaluasi proses dilakukan untuk mengetahui sampai sejauh mana produk telah berhasil diterapkan dan komponen yang harus diperbaiki. Evaluasi dilakukan dengan menguji reaksi peserta terhadap 4 pernyataan mengenai waku pelatihan, kesulitan penggunaan e-learning, kemudahan mendownload, serta meng-upload materi. Hasil perhitungan score untuk indikator proses dengan 10 responden dapat dilihat pada Tabel 7.

Tabel 7. Hasil Perhitungan Scoring Evaluasi Proses

\begin{tabular}{|c|c|c|c|c|c|c|c|}
\hline \multirow[b]{2}{*}{ No. } & \multirow[b]{2}{*}{ Indikator } & \multicolumn{5}{|c|}{ Tanggapan Responden } & \multirow[b]{2}{*}{ SKOR } \\
\hline & & $\begin{array}{c}\text { STS } \\
(1)\end{array}$ & $\begin{array}{l}\text { TS } \\
\text { (2) }\end{array}$ & $\begin{array}{l}\mathrm{KS} \\
\text { (3) }\end{array}$ & $\begin{array}{c}\mathrm{S} \\
(4)\end{array}$ & $\begin{array}{l}\text { SS } \\
\text { (5) }\end{array}$ & \\
\hline 1 & $\begin{array}{l}\text { Perbandingan waktu pelatihan } \\
\text { dengan banyaknya materi sangat } \\
\text { sesuai }\end{array}$ & 0 & 0 & 4 & 5 & 1 & 3,7 \\
\hline 2 & $\begin{array}{l}\text { Tidak ada kesulitan belajar saat } \\
\text { menggunakan e-larning }\end{array}$ & 0 & 0 & 2 & 6 & 2 & 4 \\
\hline 3 & $\begin{array}{l}\text { Saya dapat mengunduh/ download } \\
\text { file di e-learning }\end{array}$ & 0 & 0 & 0 & 3 & 7 & 4,7 \\
\hline 4 & $\begin{array}{l}\text { Saya dapat menyertakan / upload } \\
\text { file di e-learning }\end{array}$ & 0 & 0 & 1 & 2 & 7 & 4,6 \\
\hline \multicolumn{7}{|c|}{ Rata-rata } & 4.2 \\
\hline
\end{tabular}

Mayoritas peserta pelatihan mampu mengunduh dan meng-upload materi e-learning, sehingga mendapatkan skor yang cukup besar. Namun, pernyataan mengenai waktu pelatihan memiliki tanggapan negative, yaitu sebanyak 4 orang tidak setuju. Hal ini dikarenakan peserta memberikan tanggapan yang cukup antusias ketika pelatihan. Beberapa topik seperti plagiarisme dan cyberbullying mendapat respon yang cukup besar sehingga diskusi memakan waktu yang lama. Dalam penelitian sejenis, proses pelaksanaan pembelajaran memang sering terganggu jika tidak ditentukan oleh keteraturan perencanaan pembelajaran, baik yang dilakukan oleh pengajar maupun kurikulum - sehingga perlu ditinjau ulang terhadap GGBP yang telah dirancang.

\section{Evaluasi terhadap produk}

Evaluasi produk dilakukan untuk menilai ketercapaian/keberhasilan produk. Evaluasi dilakukan dengan menguji reaksi responden terhadap 3 pernyataan mengenai kualitas $e$ learning, pengaruh motivasi belajar jika menggunakan e-learning dan kemampuan peserta mengerjakan kuis secara online. Hasil perhitungan score untuk indikator produk dengan 10 responden dapat dilihat pada Tabel 8. 
Tabel 8. Hasil Perhitungan Scoring Evaluasi Produk

\begin{tabular}{|c|c|c|c|c|c|c|c|}
\hline \multirow[b]{2}{*}{ No. } & \multirow[b]{2}{*}{ Indikator } & \multicolumn{5}{|c|}{ Tanggapan Responden } & \multirow[b]{2}{*}{ SKOR } \\
\hline & & $\begin{array}{c}\text { STS } \\
(1)\end{array}$ & $\begin{array}{l}\text { TS } \\
(2)\end{array}$ & $\begin{array}{l}\mathrm{KS} \\
(3)\end{array}$ & $\begin{array}{c}\mathrm{S} \\
(4)\end{array}$ & $\begin{array}{l}\mathrm{SS} \\
(5)\end{array}$ & \\
\hline 1 & $\begin{array}{l}\text { Kualitas tampilan e-learning sangat } \\
\text { menarik }\end{array}$ & 0 & 0 & 0 & 3 & 7 & 4,7 \\
\hline 2 & $\begin{array}{l}\text { Saya lebih termotivasi untuk belajar } \\
\text { setelah menggunakan e-learning }\end{array}$ & 0 & 0 & 4 & 5 & 1 & 3,7 \\
\hline 3 & $\begin{array}{l}\text { Tidak ada kesulitan saat mengikuti } \\
\text { kuis pada e-learning }\end{array}$ & 0 & 0 & 1 & 9 & 0 & 3,9 \\
\hline \multicolumn{7}{|c|}{ Rata-rata } & 4,1 \\
\hline
\end{tabular}

Mayoritas peserta pelatihan menyatakan "setuju" jika kualitas tampilan e-learning menarik dan tidak ada kesulitan saat mengerjakan kuis. Peningkatan motivasi peserta untuk belajar menggunakan e-learning tergolong rendah. Secara keselurahan rata-rata skor evaluasi produk adalah 4,1 atau dapat disimpulkan jika sebagian besar reponden memberikan tanggapan positif untuk evaluasi produk dengan mayoritas jawaban antara setuju hingga sangat setuju. Evaluasi produk biasanya melihat tingkat pemahaman peserta menguasai materi. Rata-rata evaluasi produk menghasilkan jawaban cukup baik meskipun tidak mencapai $100 \%$. Berdasarkan evaluasi seluruh dimensi di atas, rata-rata nilai keefektifan pelatihan digital literacy berbasis $e$ learning dapat dilihat pada Gambar 3.



Gambar 3. Grafik hasil evaluasi reaksi pengguna dengan CIPP

Gambar 3 menunjukkan skor yang diperoleh pada evaluasi reaksi tertinggi berada pada dimensi konteks dan proses. Hal ini dapat disebabkan karena besarnya minat peserta terhadap tema pelatihan dan kemudahan menggunakan e-learning. Sementara nilai terendah, yaitu berada pada dimensi input. Hal ini disebabkan kurangnya waktu belajar peserta sebelum mengerjakan kuis, sementara peserta minim dengan kemampuan digital literacy yang sesuai dengan $B C$ 's Digital Literacy framework. Dalam hal kemampuan menggunakan sarana e-learning, peserta tidak mengalami kesulitan karena pustakawan PDII-LIPI telah terbiasa mengelola perpustakaan secara digital. Namun ada beberapa saran, seperti melakukan perbaikan perencanaan pembelajaran, khususnya waktu pelatihan - sehingga materi yang disediakan dapat tersampaikan secara maksimal kepada peserta pelatihan. 


\section{KESIMPULAN}

Penelitian ini menyimpulkan bahwa guideline dan e-learning yang dirancang mendapatkan respon positif dari responden. Rata-rata perhitungan kuesioner menunjukkan nilai antara $4-4,2$, yang berarti sebagian besar peserta pelatihan memberikan tanggapan positif untuk evaluasi produk (terlihat dari jawaban "setuju" dan "sangat setuju"). Penelitian yang dilakukan sebelumnya telah berhasil mendesain sebuah pelatihan berbasis blended learning yang dapat digunakan oleh perpustakaan untuk menyelenggarakan pelatihan digital literacy dan mendukung penerapan konsep smart city di Indonesia. Peneliti menyarankan agar ditambahkan materi pengajaran melalui aplikasi, seperti penambahan konten visual (gambar, video dan audio) untuk referensi pembelajaran; serta evaluasi waktu penyelenggaran pelatihan. Selain itu, perlu dilakukan penelitian lanjutan untuk memperbaiki metode pembelajaran dengan menerapkan pelatihan kepada peserta dengan jumlah yang lebih besar, dan melibatkan para pakar litarasi digital untuk memberikan masukan mengenai modul dan rencana pembelajaran. 


\section{DAFTAR PUSTAKA}

Ayunda, W.A, Nurhadyani, Y., \& Wijaya, S.H. 2018. Development Digital Literacy GuidelineFor Smart City (In Library Perspective). Paper presented at the 1th International Conference on Library and Information Science (ICLIS), UPI, Bandung, November 7-8.

Aziz, M. \& Rehman, Z. 2018. Implementation of CIPP Model for Quality Evaluation at SchoolLevel: A Case Study. Journal of Education and Educational Development, 5(1), 189206.

Bakhti, B.Y. 2017. Evaluasi Program Model CIPP Pada Proses Pembelajaran IPA. Jurnal Inovasi Pendidikan Fisika dan Riset Ilmiah, 1(2), 75-82.

Bawden, D. 2008. Origins and Concepts of Digital Literacy, in C Lankshear \& M Knobel (eds), Digital Literacies: Concepts, Policies and Practices. Peter Lang Publishing, 126(591), 388405 .

British Columbia Public Libraries. 2017. BC'sDigital literacyFramework. https://www2.gov.bc.ca/assets/gov/education/kindergarten-to-grade-12/teach/teachingtools/digital-literacy-framework.pdf.

Hamilton, B. 2017. Library Lesson In Digital Citizenship: On Overview Of How The School Library Can Support Digital Citizenship In The Curriculum. http://ideas.demco.com/blog/library-lessons-digital-citizenship/.

Lankshear, C. \& Knobel, M. 2006. Digital Literacy and Digital Literacies: Policy, Pedagogy, and Research Considerations for Education. Digital Kompetanse, 1(1), 12-24.

Lim, M. \& Virginia, W.K. 2007. Online vs Blended learning: Differences in Instructional Outcomes and Learner Satisfaction. Journal of Asynchronous Learning Networks, 11(2), 2742.

Mahmudi, I. 2011. CIPP: Suatu Model Evaluasi Program Pendidikan. Jurnal At-Ta'dib, 6(1), 111125.

Maryuliana, S. \& Haviana, S.F.C. 2016. Sistem Informasi Angket Pengukuran Skala Kebutuhan Materi Pembelajaran Tambahan Sebagai Pendukung Pengambilan Keputusan di Sekolah Menengah Atas Menggunakan Skala Likert. Jurnal Transistor Elektro dan Informatika, 1(2), $1-12$.

Sekaran, U. \& Bougie Roger. 2013. Research Methods for Business: A Skill Building Aproach, $7^{\text {th }}$ Edition. USA: Wiley.

Setyaningrum, A. 2016. Implementasi Model Evaluasi CIPP pada Pelaksanaan Program Pendidikan dan Pelatihan di BPTT Darman Prasetyo Yogyakarta.

Sugiyono. 2017. Metode Penelitian Kuantitatif Kualitatif dan R\&D.Edisi 23. Bandung: Alfabeta. 